\title{
CINEMA, O TEMPO SOCIAL E O SEU INTÉRPRETE
}

Resumo: Entendendo a arte como uma forma particular de conhecimento é possível pensar que a sociologia tem muito a aprender com ela. Uma das teses que compartilhamos nesse ensaio é a de que a arte é capaz de realizar a síntese do tempo histórico por sua capacidade específica de ser e estar do mundo, pois, enquanto o conhecimento científico busca categorias universais, intentando reduzir ao máximo a influência dos aspectos humanos e sociais na apreensão dos fenômenos, o conhecimento estético, ainda que busque referenciais abstratos, não pode livrar-se da experiência e do mundo ao seu redor. Essa premissa, tomando como base a leitura de Fredric Jameson, vale tanto para a arte autoral como para aquela feita em série, isto é, a produção da indústria cultural. Tanto uma quanto a outra, ao seu modo, traduz o tempo social, tarefa que cabe à crítica desvendar.

Palavras chave: narrador social, sociologia da arte, cinema e tempo social, conteúdo e forma.

Abstract: By understanding art as a particular form of knowledge is possible to think that sociology has much to learn from it. One thesis that we share in this essay is that the art is able to perform the synthesis of the historical time for its specific capacity to be in the world, because, while scientific knowledge search universal categories, intending to reduce as much the influence of human and social aspects in the apprehension of phenomena, aesthetic knowledge, even if it seeks abstract referentials, can not get rid of the experience and the world around it. This premise, based on the reading of Fredric Jameson, worth as much to the art authorial as for the one performed in series, this is, the production of the cultural industry. Both one and another, in their own way, translates the social time, task that fits to criticism unravel.

Keywords: social narrator, sociology of art, film and social time, content and form.

* Professora junto à Faculdade de Filosofia e Ciências da UNESP, Câmpus de Marília. Possui doutorado em Ciências Sociais pela Universidade Estadual de Campinas (1997), pós doutorado pela Università degli Studi di Roma, "La Sapienza" (2001) e livre docência pela Faculdade de Filosofia e Ciências da UNESP (2013). E-mail: ctolen@uol.com.br. 
Partimos do princípio de que a manifestação artística é uma forma de conhecimento muito peculiar que pode revelar e compreender o mundo por apreender a vida a partir de situações concreta e historicamente determinadas. Para não ficarmos no campo das reflexões sobre a grande arte e a sua vocação para reconciliar a humanidade com a natureza, como propõe Györg Lukács a partir da escola romântica alemã, nos propomos a pensar aqui o campo das manifestações culturais, seguindo as pistas de Fredric Jameson em As marcas do visível (1995), quando observa que mesmo nas formas degradadas de manifestação artística é possível encontrar as revelações de um pensamento político e, por consequência, alguma utopia, ainda que esta apareça numa perspectiva negativa à primeira vista. Mas, é em Lukács, entretanto, que encontramos a reflexão de que a arte é uma forma de conhecimento, uma forma particular e distinta daquela proposta pela ciência pois, se o papel desta é exatamente o de revelar, dar a conhecer segundo parâmetros reconhecidos e aceitos socialmente, o papel da arte é o de representar, livremente, o real em curso, e não de traduzir a realidade em si mesma. Deste modo, propõe Lukács, a arte não tem categorias pré-estabelecidas e tampouco fixas, gozando de uma autonomia que a ciência não tem. Isso não significa dizer que haja uma "essência supra temporal" da obra de arte, mas, ao contrário, pois filiada a um ponto de vista, que muitas vezes se traduz em escolas, estilos, fórmulas para além das criações autorais (que fazem ou podem fazer escolas), a obra de arte ou a criação artística será sempre histórica. E, neste sentido, Jameson, em Marxismo e forma (1985), exorta a crítica marxista a não perder de vista que este debate encara o artista e a sua obra como produtores e produtos da história.

Filiando-me a esta perspectiva, penso que podemos dizer que existe um narrador social em cada expressão artística, constituído pela posição do artista e seu meio em relação à história, que lhe oferece conteúdo ou matéria artística. Pensando as artes narrativas, podemos dizer que às vezes o grande artista concede a palavra e faz falar um outro grupo em seu lugar, às vezes fala de si e sua gente, ou se filia ao pensamento dominante, muito 
comum na arte de entretenimento. Mas, ainda assim, tem algo a desvendar em relação à vida em curso, pois na concretude da arte podemos encontrar os elementos da vida humana captados em sua imediatez, na condição prosaica, o cotidiano, o vivido, e, por consequência, os influxos de um processo global, mesmo quando tal processo seja entendido em termos subjetivos ou metafísicos.

Deste modo, o artista dá forma às tendências de um tempo. E quando falamos em dar forma estamos afirmando uma das questões cruciais do pensamento lukacsiano que, em geral, é mal entendida quando se supõe que para este teórico haveria uma primazia do "conteúdo" em detrimento da construção formal das obras. Para Lukács, uma coisa não se desvincula da outra e enquanto o conteúdo é histórico, a forma evidencia a posição política e a interpretação que o artista faz de seu mundo. Dessa ideia nasce a questão de que da comunidade entre conteúdo e forma se extrai a filiação de classe (ou de fração de classe, ou de grupo) do artista, impressa na escritura da obra. E aqui é importante ressaltar aquilo que Jameson (1985) observa quando afirma que se a forma da arte é móvel, é fruto de uma escolha, uma filiação, ela não implica uma verdade de tipo positivista, justamente porque sendo móvel define o tipo mediação entre o artista e seu objeto, entre o homem e o produto do seu trabalho. E dado que para o pensamento dialético a realidade precede as ideias que dela se faz, a estrutura de um pensamento deve remeter-se à própria realidade, deve encontrar explicação na própria relação sujeito/objeto, artista/realidade. Ou seja, cada obra exige sua própria crítica, com base nas categorias que aciona para apreender a matéria concreta que lhe confere conteúdo. Isto significa que toda crítica que parte de um conceito a priori "engessa" as possibilidades de leitura de um produtor artístico.

Ainda neste sentido, o esforço da crítica não deve ser o de fazer análise do conteúdo especificamente, mas da sua interação na forma, que tem o poder de revelá-lo profundamente, como propõe Jameson (1985) no mesmo escrito. Este analista sugere que uma correta investigação da forma faz uma análise hermenêutica do conteúdo: "assim o processo de crítica não é tanto uma interpretação 
do conteúdo como é uma revelação dele, um desnudamento, uma restauração da mensagem original, da experiência original, que jaz sob as distorções dos vários tipos de censura que sobre ela operaram [...]" (JAMESON, 1985, p. 306). Isto porque o conteúdo já é concreto, "na medida em que é, essencialmente, experiência social e histórica" (idem). Portanto, se a arte é informada pela matéria humana vivida e, ao contrário da ciência, não tem categorias fixas, toda exegese deve dispensar qualquer categoria pré-concebida.

Só para reafirmar o já dito, isso não pressupõe nenhuma análise da obra enquanto coisa encerrada em si mesma, mas a compreensão da justa relação entre a forma acabada na obra de arte e os elementos materiais que lhe conferem pertinência. Para clarear essa ideia, vale citar uma interessante metáfora proposta por Jameson para sugerir que a compreensão de uma dada obra pode ser completa se soubermos interpretar a transformação que o artista realiza da matéria bruta: um escultor, ao ser indagado de como fizera uma determinada obra, responde que ela já existia no mármore, bastando-lhe remover as excrescências. Quer dizer, a matéria-prima está dada e carece apenas do trabalho de lapidação. Em se tratando da literatura ou do cinema, a matéria-prima é social e é responsável pelas suas características. Ao crítico caberia revelar o trabalho de lapidação e, neste processo, revelar também como isso se deu em relação à matéria que foi lapidada.

Mas, isso que Jameson chama de lapidação, ou o tratamento dado à forma, não é sempre franco, pois o processo do trabalho na sociedade burguesa é segredo cuidadosamente ocultado, uma vez que o seu desvendamento é também a revelação do sujeito histórico. Vale citar seu texto, cuja clareza é difícil reproduzir em outras palavras:

É esse, na verdade, o significado mesmo da mercadoria como uma forma, apagar os sinais do trabalho no produto, a fim de que mais facilmente esqueçamos a estrutura de classe que é sua armação organizacional. Seria de fato surpreendente se tal ocultamento do trabalho não deixasse sua marca também sobre a produção artística, tanto na forma como no conteúdo, 


\begin{abstract}
como nos mostra Adorno: "as obras de arte devem sua existência à divisão social do trabalho, à separação entre o trabalho mental e o trabalho físico. Numa tal situação, entretanto, elas aparecem sob o disfarce da existência independente; pois seu medium não é aquele do espírito puro e autônomo, mas sim o de um espírito que tendo se tornado objeto afirma agora ter superado a oposição entre os dois. Tal contradição obriga a obra de arte a ocultar o fato de que ela mesma é uma construção humana [...]". (JAMESON, 1985, p. 309).
\end{abstract}

É justamente neste processo de desvendar o trabalho que esta perspectiva crítica deve atentar para a forma de uma obra e apontar a exteriorização e os instrumentos de que dispôs o artista para abordar determinado conteúdo. Nessa confluência, entre a matéria e instrumentos cognitivos e históricos para compor uma representação, reside o que chamamos acima de narrador social da obra de arte. Como observará Jameson, sempre em Marxismo e forma, a sociedade moderna se especializa a cada dia na ocultação das relações de trabalho e, por isso mesmo, a arte moderna cada vez mais se distancia da grande forma realista do Século XIX, aquela onde o artista expunha os traços do trabalho na construção do mundo, aquela na qual ele podia traduzir em termos humanos os resultados do processo de transformação da natureza e da construção da sociedade. Entretanto dirá, cabe à crítica notar que atrás da arte abstrata, surrealista, impressionista, etc., há a epopeia do sujeito num mundo moderno, abandonado por Deus e pelo Diabo.

E se Fredric Jameson fala da arte em geral, observo em particular a arte narrativa do cinema e da literatura, não por sugerir que as demais artes não sejam passíveis dos mesmos critérios, mas por falta de instrumentos metodológicos e conhecimento dos outros campos artísticos. Isso significa, portanto, que ao sociólogo caberá o esforço de compreender também as especificidades das linguagens artísticas, dos estilos, escolas e gêneros, e recordar-se que estes são também, necessariamente, históricos. Linguagens, 
estilos, escolas não nascem no nada e aderir a determinada escola ou gênero é, portanto, assumir uma posição, ou posicionamento, diante do mundo, tentando repetir caminhos já trilhados ou posicionamentos conhecidos que, por sua vez, são frutos originários de uma ação em algum tempo e lugar. Todo conteúdo novo pede uma forma nova, diz Sergei Eisenstein (1990), e esse é o desafio do grande artista, aquele que rompe com o ponto de vista dominante em curso, com as escolas e estilos, propondo outra apreensão do real, que convencionamos chamar de autoral.

$\mathrm{E}$, em relação à narrativa fílmica, Ismail Xavier em $O$ discurso cinematográfico: a opacidade e a transparência (1977) observa que é no nível da montagem que se explicita a relação que o artista estabelece com os elementos/objetos da sua reflexão. É aí que a opção do cineasta se define entre buscar a neutralização do trabalho de construção de um dado registro do real, ocultando a sua posição enquanto sujeito; ou então demonstrando e ostentando os elementos da constituição do filme e os pontos de descontinuidade e costura que realiza. Juntar os dados do real pode dar o sentido de história, de acaso, de particularidade ou universalidade, ou ainda, falta de sentido.

Falando da grande indústria cinematográfica de Hollywood, Xavier observa como a sua forma conhecida como clássica, ou naturalista, tenta definir-se o mais próximo possível da vida em curso, como se pudéssemos observar os acontecimentos através de uma janela, tal a sua capacidade de ocultar preciosamente os rastros do trabalho de montagem:

Quando aponto a presença de critérios naturalistas, refiro-me, em particular, à construção de espaço cujo esforço se dá na direção de uma reprodução fiel das aparências imediatas do mundo físico, e a interpretação dos atores que busca uma reprodução fiel do comportamento humano, através de movimentos e reações 'naturais' (XAVIER, 1977, p. 31).

Esse estilo procura imprimir um discurso de "verdade" à ficção, produzindo o que a indústria cinematográfica apresenta 
como "autêntica imitação da vida". Esse cinema industrial, tal como na especialização do trabalho no mundo moderno, dividiu esse método de abordagem em "gêneros" específicos para apresentar uma diversidade de "universos ficcionais": os filmes históricos, os westerns, dramas, contos de fada, etc. E consagrou fundamentalmente o modelo maniqueísta do choque entre o bem e o mal absolutos, encobrindo as relações humanas autênticas, assim como a própria matéria do trabalho cinematográfico.

Ainda a propósito da montagem como elemento fundamental para definir a perspectiva da narrativa diante do real, Sergei Eisenstein, em $A$ forma do filme, comentaria que o cinema inaugural de D. W. Griffith traria uma montagem compatível com a visão liberal de mundo, com a moral piedosa sobre o conflito entre pobres e ricos, resultando no que chama de montagem paralela:

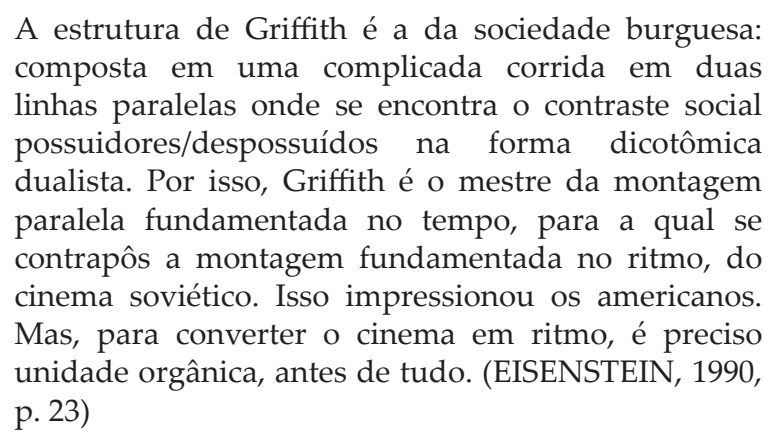

A consideração de Eisenstein é fundamental para revelar a forma como tradutora de uma perspectiva política, quando sugere que o cineasta americano desenvolveu sua arte sob um parâmetro compatível com sua leitura das relações sociais e humanas: "a montagem paralela de Griffith parece ser uma cópia de sua visão dualista de mundo, que corre através de duas linhas, rico e pobre em direção a uma 'reconciliação' hipotética onde as paralelas se cruzariam, isto é, no infinito, tão acessível quanto a 'reconciliação"' (EISENSTEIN, 1990, p. 124). O cineasta russo advogava em nome de um cinema soviético, ao qual, portanto, caberia outra forma 
de montagem, necessária para expressar outro tipo de relação do homem com a vida, com a natureza e com a história. Para o cinema do então país dos sovietes, Eisenstein propôs a montagem dialética, defendendo que uma obra com esses princípios trabalhasse com organicidade e fizesse com que o tema e o assunto fossem mergulhados no tratamento dialético até suas menores partículas, de modo que o seu impacto fosse assimilado mesmo por um conjunto de espectadores para os quais as questões tratadas não estivessem na ordem do dia: "Isto pode quebrar a resistência até do espectador cuja sujeição de classe está em franca oposição à direção tomada pelo assunto e tema da obra [...]" (EISENSTEIN, 1990, p. 18).

Tanto quanto o trabalho literário, respeitando aspectos da especificidade de linguagem, o cinema pode e deve ser analisado no conjunto, em sua estrutura e com relação às razões desta ou daquela forma de abordagem. $\mathrm{O}$ cinema que se quer verdade oculta o veículo e o trabalho de que é resultado, e isso, por si mesmo, define o tipo de relação que o artista estabelece com a arte: a de não-clareza da sua construção, historicamente determinada por ele próprio enquanto sujeito. Eisenstein tinha claro o papel do cinema inclusive de comentar a tese ou tema em questão, utilizando recursos que não resultavam em ilusão de verdade, mas que comentavam e explicitavam a leitura do seu executor, diante da qual permitia e exigia do espectador uma reação e posição. O fundamental no cinema de Eisenstein é que o veículo no qual se imprime uma determinada tese não esteja oculto. E, se o trabalho não está oculto, também não o está a relação do homem com a história e a produção da vida.

A posição de Eisenstein clareia o fato de que as narrativas, a partir da sua forma, podem integrar o homem com a vida numa perspectiva histórica, ou podem observar essa relação como coisa natural, contemplativamente, sugerindo que as ações e reações humanas sejam universais, comuns e não socialmente construídas. Sua análise do filme Intolerância, de Griffith (1916), observa que essa narrativa chega à tese de que a intolerância seria fruto do egoísmo humano, atribuindo conteúdo piedoso e moral aos 
comportamentos sociais, naturalizando o que é historicamente construído.

O que parece interessante reter ao final desta reflexão é que a arte, enquanto instrumento cognitivo, sem forma fechada, nos dará sempre a dimensão do sujeito histórico que a produz e exigirá sempre uma dupla operação para sua compreensão profunda: a do sujeito social que fala através das categorias que utiliza para fazer uma abordagem do real, e a do próprio conteúdo, ou do discurso elaborado sob um determinado ponto de vista.

É fundamental dizer que nenhuma obra artística realiza um retrato, tampouco um decalque da realidade, mesmo que o queira, mas um discurso cujo ponto de vista cabe ao crítico desvendar, assim como cabe desvendar o chão histórico que o determina. Antonio Candido observa em Literatura e sociedade (2000): não basta descrever os elementos constitutivos de uma narrativa, isto é, os costumes, os hábitos, o linguajar, manifestações de um grupo ou de uma classe. Isso não bastaria para definir o caráter sociológico de um estudo, pois seria o mesmo que descrever uma casa, seus cômodos e suas funções. É necessário discutir como se fez a casa, sob quais princípios, seus materiais e também a função de cada coisa, acrescentamos. Antonio Candido está chamando de estrutura o que também podemos chamar de forma, da qual, como dissemos, se extrai o conteúdo profundo da obra de arte porque ali se estrutura o ponto de vista do narrador social. Este, por sua vez, pode coincidir com a perspectiva do artista, mas não necessariamente, como já observamos. Dois exemplos cinematográficos aqui podem contribuir para nosso debate sobre o narrador social, acrescentando aí a questão da arte engajada e daquela massificada: Jeca Tatu (1959), feito pela Companhia de Amácio Mazzaropi, e Deus e o diabo na terra do sol (1963), filiado ao Cinema Novo, dirigido por Glauber Rocha.

É possível dizer que num filme como o Jeca Tatu haja mais verdade sobre o tempo social do que no engajado Deus e o diabo na terra do sol, feito com distância de poucos anos do primeiro. Isso porque, ao assumir o ponto de vista do desenvolvimento industrial, do urbano em detrimento do rural, do pensamento dominante, 
o narrador social do filme protagonizado por Mazzaropi punha a nu o processo em curso e advogava em favor dele. Assumindo um olhar clownesco, levantava problemas em relação à permanência dos velhos hábitos coronelistas, evidenciava a política clientelista no estado que se pensava a locomotiva da modernidade, rendia graças à indústria multinacional do cinema e da nossa incipiente indústria cultural e diluía em acordo os conflitos que o próprio filme acionava ao longo do narrado, como a expulsão dos camponeses das suas terras, o êxodo rural e o coronelismo associado ao agroindustrial nascente. Não quer dizer que seja um ponto de vista que nos agrade, muito pelo contrário, pois fechando as questões polêmicas que levanta, sugere que o remédio é rir para não chorar, e aproveitar as brechas para tirar proveito, já que o fim do Jeca, isto é, do caipira, seria inevitável. A narrativa o transforma em fazendeiro Jeca Tatu, ou seja, naquele que poderia sobreviver, apesar do atraso. Sem dúvida, esse cinema popular pode traduzir o ponto de vista dominante, inclusive as verdades para as classes populares não organizadas naquele momento, cujo silêncio daria base para o que veio a seguir na história brasileira: manda quem pode, obedece quem tem juizo. Melhor a adesão que a rebelião. Mas, é a leitura a contrapelo, como ensina Walter Benjamin, que nos dá essa verdade oculta na perspectiva clownesca da narrativa. À primeira vista, resta a tese de que as transformações em curso, ou a modernização, são necessariamente melhores que o risível e desajeitado Jeca Tatu, a quem aderimos, mas cuja identidade recusamos para nós espectadores.

Recusando-se ao tempo em curso, falando a partir da utopia, Glauber Rocha fraturaria seu filme sobre a situação camponesa em dois narradores, ou duas instâncias narrativas, uma que via a persistência do tempo presente e a outra que anunciava a revolução socialista. A primeira é narrada do ponto de vista de um pobre vaqueiro sertanejo, a segunda do ponto de vista do intelectual engajado, que dá outra leitura (outro ponto de vista de câmera, de montagem, de música) ao imediato, ao vivido, aos problemas em pauta. O primeiro conclui que não há muita saída para um homem pobre no sertão coronelista, a não ser obedecer 
a um patrão, ou então rebelar-se no messianismo ou cangaço. Osegundo,emnomedautopia, dizqueessa rebeldiaérevolucionária e que, por isso mesmo, a revolução estaria a caminho como rezava a prédica milenarista de Antônio Conselheiro: o sertão viraria mar e o mar viraria sertão, pois os camponeses pobres já haviam dados sinais desta luta na Guerra de Canudos. E para concertar essa utopia, este tempo em devir, esse narrador cria sua forma, utiliza aspectos da narrativa popular, da erudita, da recriação já proposta por Villa Lobos e pelos modernistas brasileiros, relê Eisenstein e o cinema soviético em busca da forma nova para o conteúdo novo, utópico. O sertanejo rebelado e acuado no sertão coronelista conclui que da rebeldia extraiu uma lição: assim, mal dividido, esse mundo anda errado, a terra é do homem. Não é de Deus, nem do diabo. O intelectual responde: se a terra é do homem, não é de Deus nem do Diabo, cabe ao homem fazer a história. Marx, diria: mas, não a faz necessariamente como quer. $\mathrm{O}$ narrador social, dividido entre o ponto de vista do homem comum e do intelectual, acaba deixando à vista os impasses do caminho ${ }^{1}$.

Mas, seja em Jeca Tatu seja em Deus e o diabo não é a discussão a priori do contexto histórico no qual as obras foram realizadas, ou a posição ideológica pessoal dos seus realizadores que buscamos para explicar o filme em nome de uma sociologia do cinema. Pensando as narrativas como tradução do tempo social, nos dirigimos a elas para entender aquilo que Antonio Candido definiu como o processo pelo qual o externo se torna interno, ou seja, dá estrutura às obras. Voltando à metáfora do mármore, ambos os escultores tem nas mãos a mesma matéria social, um desafia a forma original da pedra, sugere sua transformação em algo novo, desbasta, reelabora, enfrenta sua dura resistência e compõe uma obra desigual, difícil de definir à primeira vista. O outro reconhece a pedra, afirma sua natureza, compõe um alto relevo (ou baixo

\footnotetext{
${ }^{1}$ Para uma análise mais detalhada do filme Jeca Tatu, indico meu livro O rural no cinema brasileiro, São Paulo, Ed. Unesp, 2001, cap. III; e para Deus e o diabo na terra do sol ver: XAVIER, Ismail. Sertão Mar. Glauber Rocha e a estética da fome. São Paulo, Cosac\&Naif, 2012.
} 
$|42|$

Cinema, o tempo social e seu intérprete

relevo, tanto faz) e não busca alterar a sua forma original, pois entende que este é o limite dentro do qual pode operar. Ambos são artistas, ambos esculpem a pedra, mas o material com o qual operam, a concepção de cada um diante do que se pode fazer em relação ao mármore define o resultado. Sobre a ideia que fazem da matéria bruta, é bom lembrar que não estão sozinhos, que enquanto uns creem na possibilidade de sua transformação, outros creem que sua essência é aquela mesma, assim como seus limites. A explicação dessa natureza, mutável ou não, define o narrador social: seus argumentos nos interessam enquanto aquilo que define o enfrentamento da matéria e a forma final por essa adquirida.

E é interessante essa capacidade de a própria obra explicar a si e seu construtor, a posição deste diante do material trabalhado. Por isso mesmo as categorias explicativas não podem ser definidas a priori, assim como não se pode desconhecer os materiais e métodos artísticos, ou a disposição dos criadores culturais, para nossas análises sociológicas. Sobre isso, que não cabe no espaço deste ensaio, lembro as últimas palavras de Auerbach, em Mimesis, quando diz, referindo-se à interpretação literária:

O método da interpretação de textos deixa à discrição do intérprete um certo campo de ação: pode-se escolher dar ênfase como preferir. Contudo, aquilo que afirma deve ser encontrável no texto. [...] Em pesquisas desta espécie, não se mexe com leis, mas com tendências e correntes que se entrecruzam e complementam da forma mais variada possível (AUERBACH, 2004, p. 502).

E, notando como a arte reclama um crítico disposto a deixar-seimplicar pelas obras, confirma: "Asminhasinterpretações são dirigidas, sem dúvida, por uma intenção determinada [...] mas esta intenção só ganhou forma paulatinamente, sempre durante o jogo com o texto, e, durante longos trechos, deixei-me levar pelo texto". (AUERBACH, 2004, p. 501). 


\section{Bibliografia}

ARANTES, Paulo Eduardo. Sentimento da dialética na experiência intelectual brasileira: dialética e dualidade segundo Antonio Candido e Roberto Schwarz. Rio de Janeiro: Paz e Terra, 1992.

AUERBACH, Erich. Mimesis: a representação da realidade na literatura ocidental. 5a ed., São Paulo: Perspectiva, 2004.

BENJAMIN, Walter. O narrador, in Obras escolhidas, vol I, 6a edição, trad. Sérgio Paulo Rouanet, São Paulo: Brasiliense, 1993.

CANDIDO, Antonio. Literatura e sociedade: estudos de teoria e história literária. 8. ed. São Paulo: T. A. Queiroz, 2000.

EISENSTEIN, Sergei. A forma do filme. Rio de Janeiro, Zahar,1990.

JAMESON, Fredric. Marxismo e Forma. Teorias dialéticas da Literatura no século XX. São Paulo: Hucitec, 1985.

. As marcas do visível. Rio de Janeiro: Graal, 1995.

LUKÁCS, Györg . Introdução à uma estética marxista. Rio de Janeiro: Civilização Brasileira, 1978.

XAVIER, Ismail. O Discurso Cinematográfico $-A$ opacidade e a transparência. Rio de Janeiro: Paz e Terra, 1977.

\section{Filmografia}

Deus e o diabo na terra do sol, dir. Glauber Rocha, Brasil, 1963.

Jeca Tatu, dir. Milton Amaral, Brasil, 1959. 